\title{
Effect of controlled ovarian hyperstimulation on puberty and estrus in mice offspring
}

\author{
Jiahui Ding, Xiujuan Tan, Kunkun Song, Wenwen Ma, Jing Xiao and Mingmin Zhang \\ Institute of Integrated Traditional Chinese and Western Medicine, Tongji Hospital, Tongji Medical College, \\ Huazhong University of Science and Technology, Wuhan, Hubei, People's Republic of China \\ Correspondence should be addressed to M Zhang; Email: mmzhangeins@163.com
}

\begin{abstract}
Controlled ovarian hyperstimulation $(\mathrm{COH})$ is widely used for the treatment of infertility, while the long-term effects of $\mathrm{COH}$ on the reproductive function in female offspring are currently unknown. Based on the fact that $\mathrm{COH}$ could cause high E2 levels in women throughout pregnancy and excess estrogenic exposure during fetal development is harmful to subsequent adult ovarian function, we assumed the hypothesis that $\mathrm{COH}$ disrupts reproductive function in female offspring. To test this hypothesis, $\mathrm{COH}$ was induced in mice to obtain female offspring by pregnant mare serum gonadotropin (PMSG) and HCG, and then we evaluated pubertal transition, serum levels of E2, anti-Mullerian hormone (AMH), FSH and LH, mRNA expressions of Esr1, Amhr2, Fshr and Lhcgr in ovaries, number of follicles and ovarian histology. We also investigated the apoptosis of follicles by TUNEL; the mRNA expressions of Fas, FasL, Bax, BCl2, and caspase 3, 8 and 9 by quantitative real-time PCR; and the protein expressions of cleaved-caspase (CASP) 3, 8 and 9 by Western blot. Moreover, we further observed estrous cyclicity in young adult offspring, performed follicle counting and measured the level of $\mathrm{AMH}$ in both serum and ovary. $\mathrm{COH}$ could induce detrimental pregnancy outcomes, as well as delayed pubertal transition and irregular estrous cycle due to the aberrant growth and maturation of follicles in female offspring. Our novel findings add new evidence to better understand the potential risks of $\mathrm{COH}$ on the reproductive function in female offspring, raising the awareness that $\mathrm{COH}$ could exert adverse effects on female offspring, rather than just obtain more oocytes for fertilization.

Reproduction (2017) 154 433-444
\end{abstract}

\section{Introduction}

Assisted reproductive technology (ART) is widely applied in infertility treatments. According to the European Society of Human Reproduction and Embryology (ESHRE), nearly 1269 cycles per million inhabitants were performed in 17 European countries and the number of treatment cycles is still growing in Europe, with more than 600,000 treatment cycles recorded in 2011 (European et al. 2016). Controlled ovarian hyperstimulation $(\mathrm{COH})$, apart from being routinely applied to achieve more fully mature oocytes in ART procedures, is also used without oocytes fertilization and transference in vitro. Interestingly, the number of infants born in the United States with $\mathrm{COH}$ treatments in 2005 is 2-6 times higher than that conceived through ART ovulation treatments (Schieve et al. 2009). Consequently, in regard to the large number of patients undergoing $\mathrm{COH}$ treatment, the total impact of $\mathrm{COH}$ treatments should be given more attention.

Many studies have evoked concerns that $\mathrm{COH}$ might exert various detrimental effects on offspring. Clinical studies have found that the high maternal serum estradiol environment during pregnancy as a result of $\mathrm{COH}$ can increase the risks of low birth weight and small-forgestational-age birth, and induce elevated levels of total cholesterol and low-density lipoprotein cholesterol in newborns (Hu et al. 2014, Meng et al. 2015). A prospective, assessor-blinded follow-up research has revealed that higher systolic blood pressure (SBP) are presented in 4-year-old offspring born with $\mathrm{COH}$ (Seggers et al. 2014); subsequently, positive direct effects of $\mathrm{COH}$ on SBP percentiles and subscapular skinfold thickness have been found by the same research group (La et al. 2014). Moreover, animal experiments are also conducted with special emphasis on $\mathrm{COH}$ offspring. In mice, the methylation pattern of imprinted genes in the sperm of male offspring can be altered by $\mathrm{COH}$ in mother (Stouder et al. 2009), and the effect of $\mathrm{COH}$ on fatty acid composition in adipose tissue and liver of male offspring has been reported (Wang et al. 2013). However a series of studies have suggested no influence of $\mathrm{COH}$ on other different systems of offspring, including the risk of cancer (Klip et al. 2001, Brinton et al. 2004, Gao et al. 2014), dysmorphic features (Seggers et al. 2012), fertility and sexual behavior of male offspring (Wei et al. 2014), 
and neurological outcome (Schendelaar et al. 2014). Since there is no consensus regarding the detrimental effects of $\mathrm{COH}$, further investigation is needed for the improvement and understanding of the influences on offspring conceived through $\mathrm{COH}$ treatments for infertility.

Therefore, although a growing number of studies have attempted to explore the effects of $\mathrm{COH}$ on offspring and the underlying mechanisms, there are as yet no researches focused on the assessment of the longterm effect of $\mathrm{COH}$ on reproductive system in female offspring. However the research about the long-term influences of $\mathrm{COH}$ in human population is faced with many difficulties such as the follow-up of $\mathrm{COH}$ offspring and inadequate exploration of underlying mechanisms.

Thus, to test the hypothesis that $\mathrm{COH}$ might exert adverse effects on female offspring, we used mice as the study model to determine the effects of $\mathrm{COH}$ on pubertal transition and estrous cyclicity in female offspring from $\mathrm{COH}$ mothers, and explore the potential associated underlying mechanisms.

\section{Materials and methods}

\section{Animals and treatments}

Eight-week-old female mice and ten-week-old male mice of Kunming breed were obtained from the Laboratory Animal Center of Tongji Medical College, Huazhong University of Science and Technology. All experimental procedures were approved by the Ethics Committee, Tongji Medical College of Huazhong University of Science and Technology.

The overview of experimental design is shown (Fig. 1). The mice were housed under specific pathogen-free conditions with optimal temperature and humidity with $12 \mathrm{~h}$ light: $12 \mathrm{~h}$ darkness rhythm and fed ad libitum. Upon arrival, female mice underwent one-week acclimation period without any experimental intervention. After the acclimation, the mice were observed daily for vaginal smears and only mice showing stable estrous cycles for two rounds were chosen to be superovulated with an intraperitoneal injection of $7.5 \mathrm{IU}$ pregnant mare serum gonadotropin (PMSG; Hangzhou Animal Medicine Factory, China) in diestrus phase followed by $7.5 \mathrm{IU}$ HCG (Lizhu Pharmaceutical Factory, China) $48 \mathrm{~h}$ later. Controls were injected with the normal saline at the appropriate times.

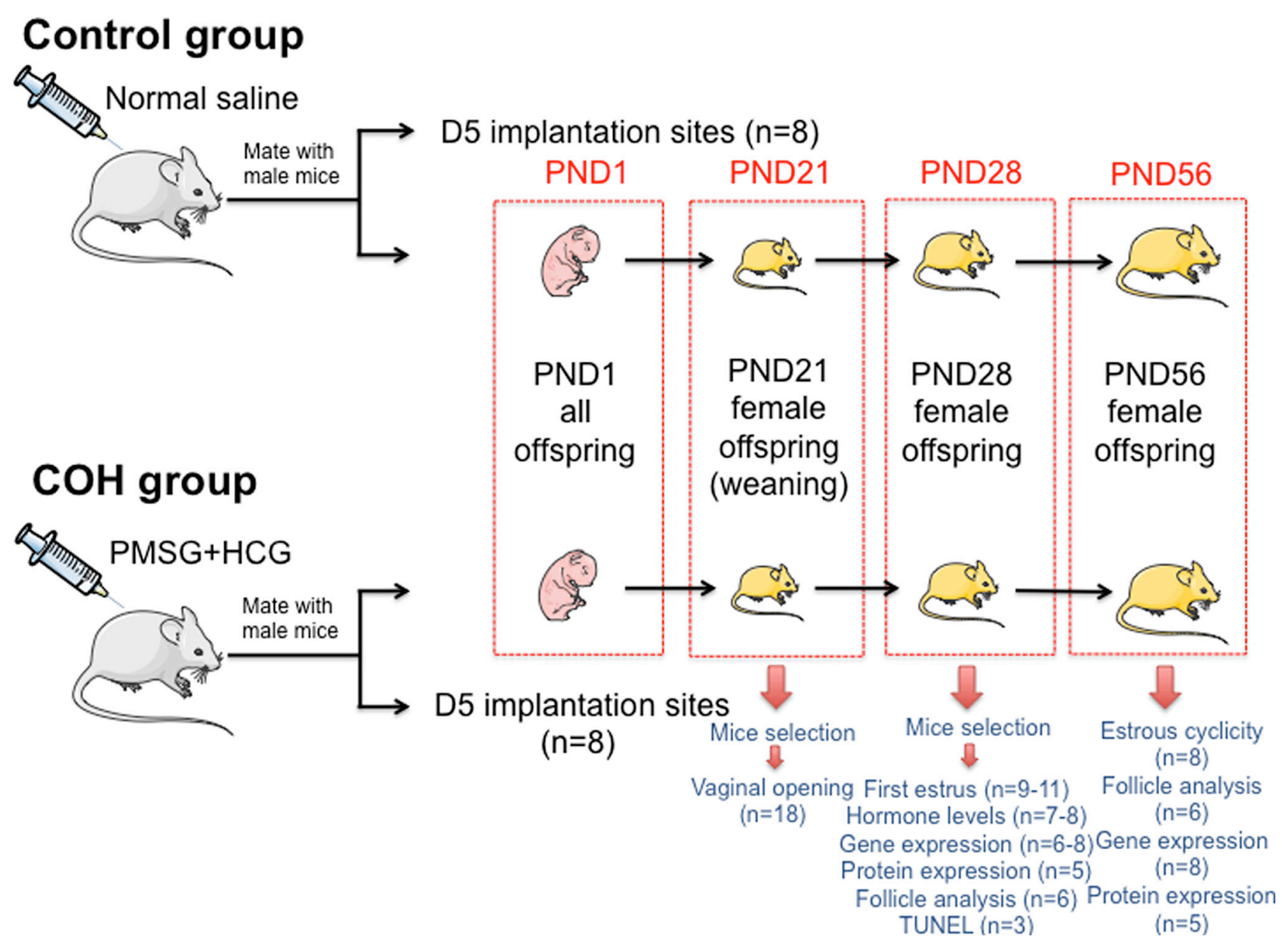

Figure 1 Overview of experimental design. Implantation sites were counted on D5 between control group and COH group. Offspring on PND1, PND21, PND28 and PND56 from the two groups were selected for detailed observation and analyses, and the numbers of animals for observations and analyses were presented. 
After superovulation, the females were mated with fertile males. As for the control group, female mice were caged with fertile males in estrus phase. Mating was confirmed by the appearance of a vaginal plug the next morning and the day was designated day 1 of gestation.

The vaginal plug-positive females of the two groups were divided into two parts, one was for the analysis of the number of implantation sites on D5 $(n=8)$, and the other was for the obtainment of offspring $(n=11)$. As for the obtainment of offspring, the vaginal plug-positive females were kept individually in cages for gestation period. The spontaneous delivery day was determined through observation of pregnant mice twice daily. The day of delivery was considered as postnatal day 1 (PND1) of age of the neonates. The number of live/dead fetuses per pregnancy and the lengths of gestations were recorded, and the pregnancy loss rate was calculated.

All pups were weaned to an ad libitum diet until PND21, and female offspring were killed when pre-pubertal (PND28) or when young adult (PND56), blood samples were collected and centrifuged at $3000 \mathrm{~g}$ for $15 \mathrm{~min}$ at $4^{\circ} \mathrm{C}$. After centrifugation, the serum was separated and stored at $-80^{\circ} \mathrm{C}$ until assayed for hormones. Ovaries were removed for morphological analysis and snap frozen for RNA and protein extraction.

\section{Evaluation of pubertal transition and estrous cyclicity}

Since nutrition will affect the development of reproductive system (Chan et al. 2015), we measured BMI of female offspring on PND21 and PND28, and set the average of BMI (0.5 for PND21 and 0.6 for PND28) as the standard; average $\pm 10 \% \times$ average of $\mathrm{BMI}$ was considered to be the selection criteria for further comparison. Female offspring from the control group and $\mathrm{COH}$ group were selected based on similar BMI on PND21, and were observed every day for vaginal opening. After vaginal opening, BMIs of selected offspring were checked again according to the criteria on PND28, and were inspected daily for vaginal lavages in order to identify the age at first estrus. A true first estrus was considered to present the cornified cells in the vaginal lavages followed by at least 2 days of predominately leukocytes in lavages (Prevot et al. 2003). Furthermore, to assess the regularity of estrous cycle in young adult (PND56) female offspring, vaginal smears of selected offspring were examined daily from PND56 for 4 weeks.

\section{Quantitative analysis of ovarian follicles}

For follicle counting, ovaries of pre-pubertal (PND28) female offspring were collected and fixed overnight in $4 \%$ paraformaldehyde (PFA), dehydrated, embedded in paraffin, and sectioned for hematoxylin and eosin staining. Five micrometer-thick sections were serially cut and every 10th section was observed for follicle counting in a blinded manner. Follicles with visible oocyte nuclei were counted. According to the previously described follicle classification (Durlinger et al. 1999, Detti et al. 2013), the number of follicles at different developmental stages was recorded; specifically, follicles were divided into 5 categories: primordial, primary, secondary, tertiary and atretic follicles. As the number of secondary and tertiary follicles ranges a lot with the follicle cycle selection, we only assess the number of primordial, primary and atretic follicles on PND56. Images were collected on an Olympus DP73 upright microscope (Olympus) with cellSens Standard acquisition software. Micrographs were analyzed by Adobe Photoshop CS6 software (Adobe Systems Inc., San Jose, CA, USA).

\section{TUNEL assay}

Apoptosis of follicle was evaluated in ovarian sections from PND28 female offspring, detected by TUNEL assay using In Situ Cell Death Detection Kit (Roche). The procedures followed the previous description (Grasa et al. 2015). Images were collected on an Olympus DP73 upright microscope (Olympus) with cellSens Standard acquisition software. Micrographs were analyzed by Adobe Photoshop CS6 software (Adobe Systems Inc.).

\section{Analysis of serum hormone levels}

Serum levels of anti-Mullerian hormone $(\mathrm{AMH})$ in PND28 and PND56 female offspring, and FSH, LH and estradiol (E2) in PND28 female offspring were measured by commercially available ELISAs (Cloud-Clone Corp., Houston, USA) and radioimmunoassay (RIA) (Beijing North Institute of Biological

Table 1 Primer sequences.

\begin{tabular}{llll}
\hline Gene name & Sequence accession number & Forward $\left(5^{\prime}-3^{\prime}\right)$ & Reverse $\left(5^{\prime}-3^{\prime}\right)$ \\
\hline Amhr2 & XM_006520293 & TGCGTTTCTCCCAGGTAATCC & TACTGAGTCAAGTAGTGGCATAAGG \\
Fshr & NM_013523 & CTCTGCCAAGATAGCAAGGTGAC & GGTCCCCAAATCCAGAAAATGA \\
Lhcgr & NM_013582 & GGTGCTTTTACAAACCTCCCTC & CGAGATTAGCGTCGTCCCA \\
Esr 1 & NM_007956 & CAAGGTAAATGTGTGGAAGGCA & ATGGGAAGAATGAGAAGGAGC \\
Fas & NM_007987 & TCCTGCCTCTGGTGCTTGCT & CAGTTTCACGAACCCGCCTC \\
FasL & NM_010177 & GTGAGTTCACCAACCAAAGCCT & GACCTTGTGGTTTAGGGGCTG \\
Casp8 & NM_001080126 & CTTGAAGGAAGGGAAGAGTTGC & CACTGTCTTGTTCTCTTGGCGA \\
Bax & NM_007527 & GCCTTTTTGCTACAGGGTTTCAT & TATTGCTGTCCAGTTCATCTCCA \\
BCl2 & NM_009741 & TGACTTCTCTCGTCGCTACCGT & CCTGAAGAGTTCCTCCACCACC \\
Casp9 & NM_001277932 & GAGGTGAAGAACGACCTGACTG & CTCAATGGACACGGAGCATC \\
Casp3 & NM_009810 & GTCTGACTGGAAAGCCGAAAC & GACTGGATGAACCACGACCC \\
Actb & NM_007393 & GTGACGTTGACATCCGTAAAGA & GTAACAGTCCGCCTAGAAGCAC \\
\hline
\end{tabular}


Technology, Beijing, China) according to the manufacturer's recommended instructions.

\section{Quantitative Real-Time PCR}

Gene expressions of Amhr2, Fshr, Lhcgr, Esr1, Fas, FasL, caspase8, Bax, BCl2, caspase9, caspase3 and $\beta$-actin as the reference had been detected in female offspring. Total RNA from ovaries were isolated by RNAiso Plus (TaKaRa) and their concentration and purity were measured by a Nucleic Acid/ Protein Analyzer (Thermo Fisher Scientific). Then cDNA were synthesized with a PrimeScript RT reagent kit (TaKaRa) in a reaction volume of $20 \mu \mathrm{L}$. Quantitative real-time PCR (qPCR) analysis was performed with SYBR Green qPCR kit (TaKaRa) on the Applied Biosystems StepOne Real-Time PCR System (Applied Biosystems) according to manufacturer's instructions. Forty cycles were set for reaction and each sample was run in triplicate $(n=6)$. The amplification conditions were as follows: initial denaturation for $30 \mathrm{~s}$ at $95^{\circ} \mathrm{C}, 40$ cycles of $5 \mathrm{~s}$ at $95^{\circ} \mathrm{C}$, annealing and elongation for $30 \mathrm{~s}$ at $60^{\circ} \mathrm{C}$. $\beta$-Actin was used as the normalization control. The primer sequences were obtained from GenBank of National Center for Biotechnology Information $(\mathrm{NCBI})$ database and verified, as well as provided in details (Table 1), and $2-\triangle \Delta C T$ (Livak \& Schmittgen 2001) method was used to calculate the fold change in gene expression.

\section{Western blot analysis}

We analyzed the protein expressions of cleaved-caspase3, cleaved-caspase8 and cleaved-caspase9 in PND28 female offspring, and AMH in PND56 female offspring. The ovarian tissues were lysed in RIPA lysis buffer (Goodbio Technology Co., Wuhan, China) supplemented with protease inhibitors (Goodbio Technology Co.), and the concentration of proteins were measured by bicinchoninic acid (BCA) assay kit (Goodbio Technology Co.). Then protein samples were loaded onto an SDS-PAGE and transferred onto PVDF membranes. $5 \%$ non-fat dry milk in $0.5 \%$ TBS-Tween was used to block

Table 2 The effects of $\mathrm{COH}$ on reproductive performance.

\begin{tabular}{|c|c|c|}
\hline Groups & Control & $\mathrm{COH}$ \\
\hline $\begin{array}{l}\text { D5 } \\
\text { implantation } \\
\text { sites }\end{array}$ & $13.75 \pm 1.67$ & $20.13 \pm 2.03^{* * *}$ \\
\hline $\begin{array}{l}\text { Gestation } \\
\text { period (days) }\end{array}$ & $20(19,20)$ & $21(20,22)^{* * *}$ \\
\hline $\begin{array}{l}\text { Total no. of live } \\
\text { fetuses }\end{array}$ & $140(n=11)$ & $99(n=11)$ \\
\hline $\begin{array}{l}\text { No. of live } \\
\text { fetuses }\end{array}$ & $13(10,15)$ & $12(0,16)$ \\
\hline $\begin{array}{l}\text { Total no. of } \\
\text { dead fetuses }\end{array}$ & $0(n=11)$ & $55(n=11)$ \\
\hline $\begin{array}{l}\text { No. of dead } \\
\text { fetuses }\end{array}$ & 0 & $0(0,8)^{*}$ \\
\hline $\begin{array}{l}\text { Pregnancy loss } \\
\quad(\%)\end{array}$ & $\begin{array}{l}5.45(13.75-13 / 13.75) \\
\quad \times 100\end{array}$ & $\begin{array}{l}40.39(20.13-12 / 20.13) \\
\quad \times 100\end{array}$ \\
\hline
\end{tabular}

Data with a normal distribution represent mean \pm S.D., and data with a skewed distribution represent medians (first quartile, third quartile). ${ }^{*} P<0.05$ and ${ }^{* * *} P<0.001$ when compared to control group.

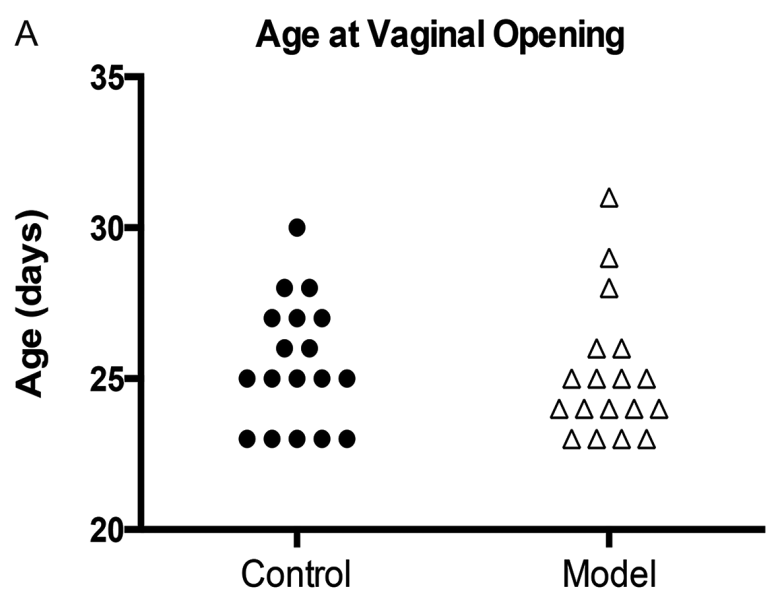

B Age at First Estrus

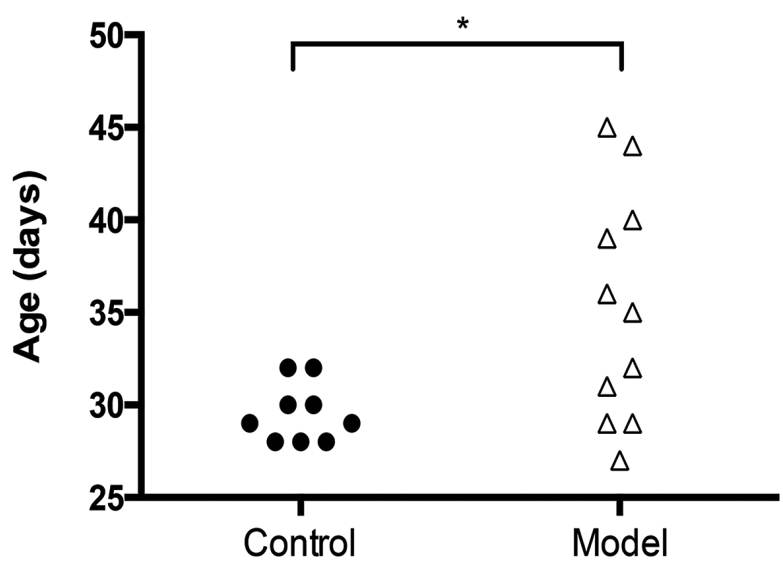

C Days Between Vaginal Opening and First Estrus

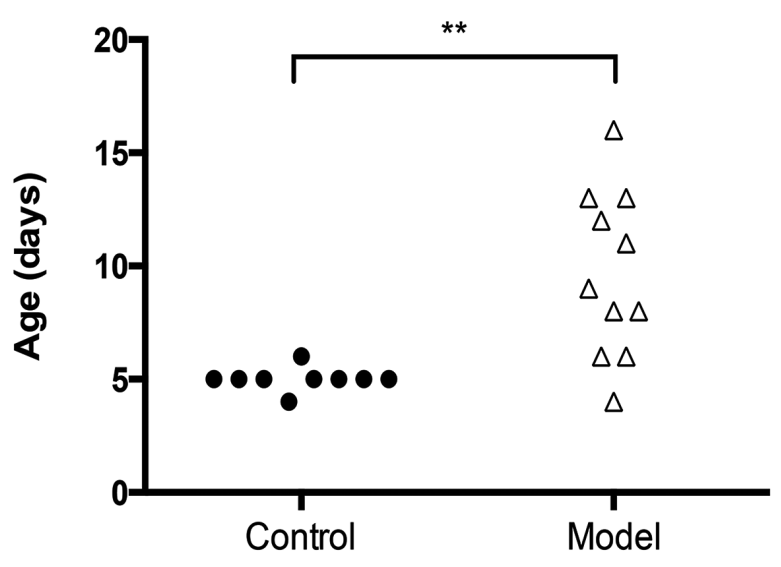

Figure 2 Female offspring of $\mathrm{COH}$ mice exhibited delayed first estrus. (A) Comparison of the age at vaginal opening between female offspring from control group and $\mathrm{COH}$ group. $n=18$. (B) Comparison of the age at first estrus between female offspring from two groups. $n=9-11$. (C) Comparison of the time between vaginal opening and first estrus between the two groups. $n=9-11 .{ }^{*} P<0.05$ and ${ }^{* *} P<0.01$ when compared to the offspring from naturally conceived mice. 


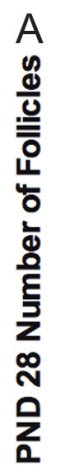
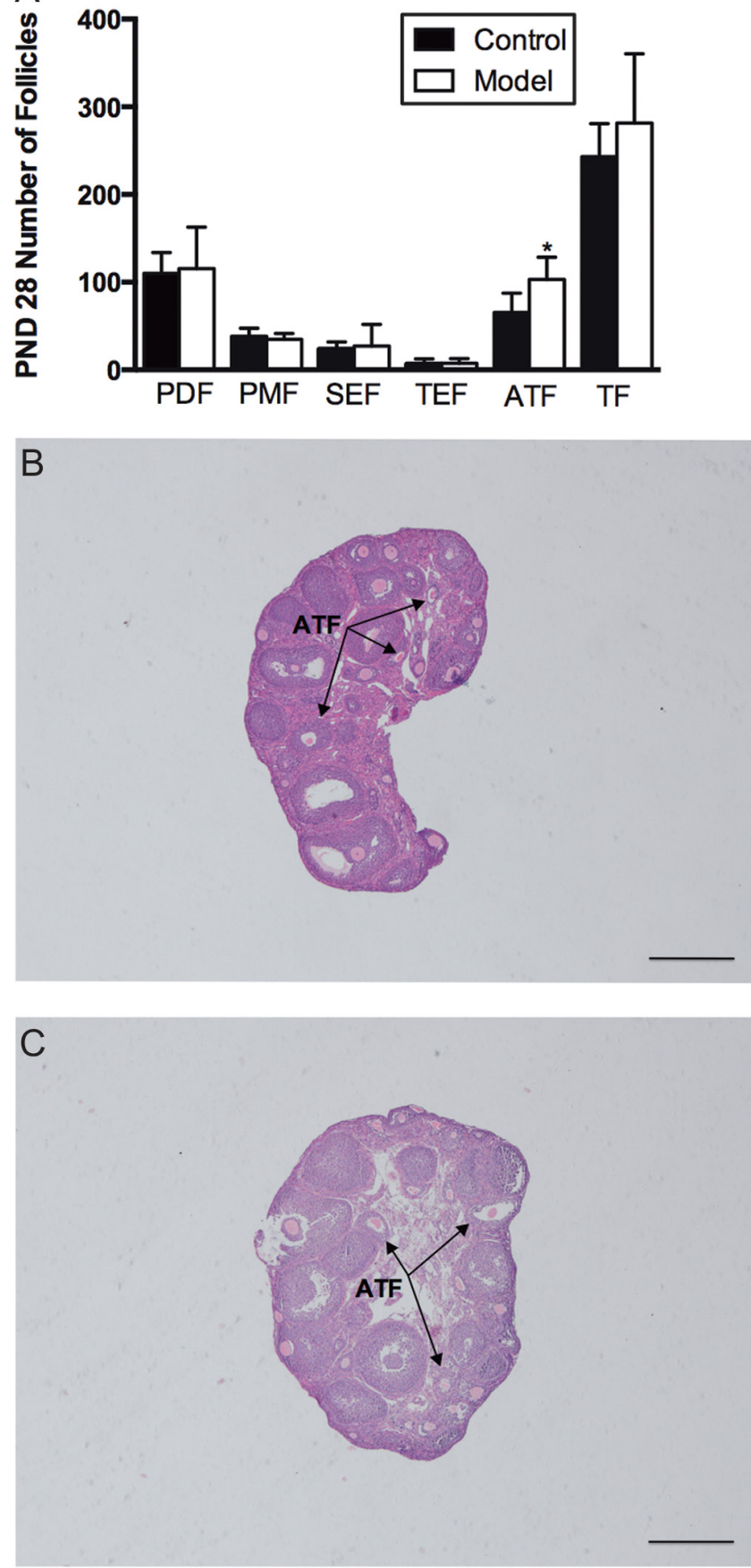

Figure $3 \mathrm{COH}$ female offspring showed more atretic follicles on PND28. (A) Comparison of percentages of follicles at different developmental stages between control group and $\mathrm{COH}$ group. $n=6$, data represent mean \pm S.D. $* P<0.05$ when compared with control group. PDF, primordial follicles; PMF, primary follicles; SEF, secondary follicles; TEF, tertiary follicles; ATF, atretic follicles; TF, total follicles. (B) Representative photographs of ovaries of offspring from control group, bar $=200 \mu \mathrm{m}$. (C) Representative photographs of ovaries of offspring from $\mathrm{COH}$ group, bar $=200 \mu \mathrm{m}$. Arrows indicate atretic follicles. non-specific binding sites. cleaved-caspase3 (\#9664; 1:1000 dilution; Cell Signaling Technology), cleaved-caspase8 (\#8592; 1:1000 dilution; Cell Signaling Technology), cleaved-caspase9 (\#9509; 1:1000 dilution; Cell Signaling Technology) and AMH (MAB1426; 1:500 dilution; R\&D Systems) were detected by primary antibodies, which were followed by horseradish peroxidase (HRP)-conjugated anti-rat secondary antibody (GB23302; 1:3000 dilution; Goodbio Technology Co.). $\beta$-Actin was detected using primary antibody (GB13001-1; 1:1000 dilution; Goodbio Technology Co.) and HRP-conjugated anti-rabbit secondary antibody (GB23303; 1:3000 dilution; Goodbio Technology Co.). Bands were exposed by ECL kit (G2014; Goodbio Technology Co.). Finally, AlphaEaseFC software (Alpha Innotech Inc., California, USA) was used to analyze the relative protein expression.

\section{Statistical analysis}

All data were analyzed by SPSS 20.0 software package (SPSS). Continuous variables with a normal distribution were presented as means \pm S.D. The unpaired Student's two-tailed $t$ test was used for comparisons between two groups. The remaining continuous variables showing a skewed distribution were expressed as medians (first quartile, third quartile) and the intergroup differences were compared using Mann-Whitney $U$ test. The statistical significance was considered as $P<0.05$.

\section{Results}

\section{The effects of $\mathrm{COH}$ on reproductive performance}

To determine the effects of $\mathrm{COH}$ on reproductive performance, we assessed the number of implantation sites on D5, the length of gestation period, the number of live and dead fetuses, and the percentage of pregnancy loss (Table 2). Compared to the control group, the number of implantation sites on D5 was increased in $\mathrm{COH}$ group (mean: 13.75 vs $\mathrm{COH} 20.13 ; P<0.001$ ), but the number of live fetuses in $\mathrm{COH}$ group was no more

Table 3 CVs of qPCR.

\begin{tabular}{lcccc}
\hline & \multicolumn{5}{c}{ CV (\%) } \\
\cline { 2 - 5 } Gene & D28 Control & D28 COH & D56 Control & D56 COH \\
\hline Amhr2 & 27.27 & 29.55 & 21.62 & 35.74 \\
Fshr & 10.45 & 31.35 & - & - \\
Lhcgr & 37.21 & 30.43 & - & - \\
Esr1 & 31.20 & 38.54 & - & - \\
Fas & 28.16 & 18.83 & - & - \\
FasL & 32.89 & 25.61 & - & - \\
Casp8 & 25.86 & 9.91 & - & - \\
Bax & 34.31 & 19.99 & - & - \\
Bcl2 & 35.84 & 24.91 & - & - \\
Casp9 & 24.99 & 28.45 & - & - \\
Casp3 & 23.96 & 28.64 & - & - \\
\hline
\end{tabular}

- represents that genes were not evaluated in ovaries of D56 female offspring. 

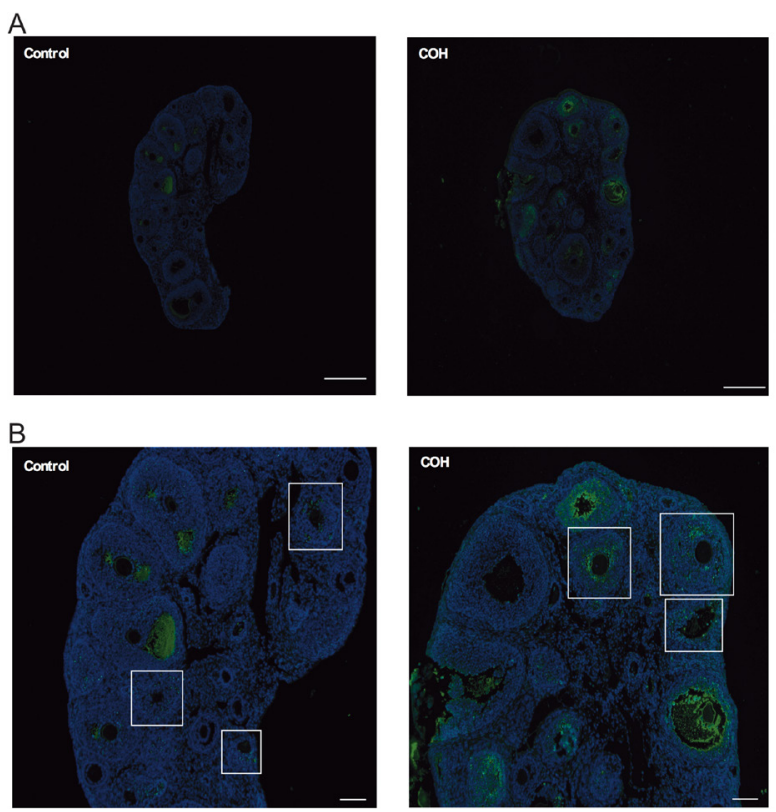

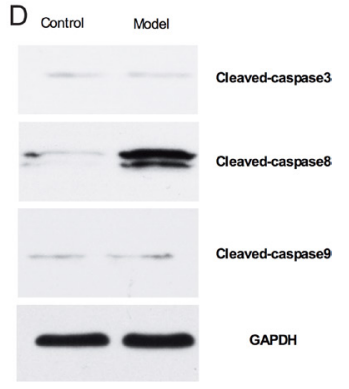

C

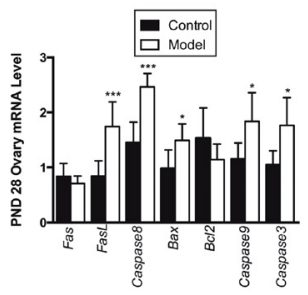

Figure 4 TUNEL analysis: genes and proteins detection in ovaries of PND 28 female offspring. (A) Representative images of ovary sections detected by TUNEL, bar $=200 \mu \mathrm{m}$. (B) Representative high-power photomicrographs of ovary sections detected by TUNEL, bar $=50 \mu \mathrm{m}$. White box refers to atretic follicles undergoing apoptosis of granulosa cells. (C) Ovarian expression levels of specific genes involved in apoptosis of granulosa cells (Fas, FasL, Caspase8, Bax, Bcl2, Caspase9 and Caspase3) in female offspring on PND28 from control group and $\mathrm{COH}$ group. Fold change

value was normalized to $\beta$-actin. $n=6-8$, data represent mean \pm S.D. ${ }^{*} P<0.05$ and $* * * P<0.001$ vs the offspring from control group. (D) Protein expression levels of cleaved-caspase3, cleaved-caspase8 and cleaved-caspase9 in ovaries of PND28 female offspring $(n=5)$. GAPDH was considered as the reference. than that of the control group (median: 13 vs $\mathrm{COH} 12$ ), and the number of live fetuses in $\mathrm{COH}$ group varied in a wide range. Apart from this, the large number of dead fetuses was discovered in $\mathrm{COH}$ mice, while no dead fetus was observed in naturally pregnant mice (total: 0 vs $\mathrm{COH} 55 ; n=11$ ). Additionally, gestation period was significantly extended in $\mathrm{COH}$ group (median: 20 vs $\mathrm{COH} 21 ; P<0.001$ ), and the comparison of pregnancy loss revealed that $\mathrm{COH}$ mice suffered a higher percentage of pregnancy loss (5.45\% vs $\mathrm{COH} 40.39 \%)$.

\section{The effects of $\mathrm{COH}$ on pubertal transition of female offspring}

To investigate whether $\mathrm{COH}$ affected pubertal transition of female offspring, we assessed the age at vaginal opening and first estrus in female offspring. Between the two groups, no significant difference in the age at vaginal opening was found (Fig. 2A). However, compared to the control group, delayed first estrus was observed in the model group $(P<0.05)$ (Fig. 2B). As a result, the time between vaginal opening and first estrus of the model group was significantly longer than that of the control group $(P<0.01)$ (Fig. $2 \mathrm{C})$.

To determine whether $\mathrm{COH}$ affected follicle development before pubertal transition, we performed follicle analysis in pre-pubertal female offspring on PND28 before the presentation of first estrus. Our results suggested that the number of atretic follicles was obviously increased in $\mathrm{COH}$ female offspring (Fig. 3A), and the quantitative evaluation was confirmed by the morphological analysis of ovaries of the two groups (Fig. 3B and C).

Apart from the fact that the number of atretic follicles was increased in $\mathrm{COH}$ female offspring, we explored whether the apoptosis of ovarian granulosa cells was also enhanced in $\mathrm{COH}$ female offspring by TUNEL assay. As our data showed, there was an increase in TUNEL staining of atretic follicles of $\mathrm{COH}$ female offspring when compared to the control group (Fig. 4A and B). Furthermore, the expressions of relevant genes participating in apoptosis of granulosa cells were analyzed by qPCR; in contrast, the expressions of FasL, caspase8, Bax, caspase9 and caspase 3 were significant higher in ovary of $\mathrm{COH}$ female offspring on PND28 (Fig. 4C). In our further study, we investigated the protein expression levels of cleaved-caspase3, cleavedcaspase8 and cleaved-caspase9 in ovaries of PND28 female offspring, and discovered that the expression of cleaved-caspase8 was increased, while no significant difference was found in the expressions of cleavedcaspase 3 and cleaved-caspase9 (Fig. 4D).

In addition, to explore whether delayed first estrus in model group was associated with low hormone levels and reduced hormone receptor gene expressions, we measured serum AMH, FSH, LH and estradiol, and evaluated gene expressions of Amhr2, Fshr, Lhcgr and Esr1 in ovaries of PND28 female offspring. The serum levels of $\mathrm{LH}$ and E2 were significantly reduced in model group, while FSH and AMH were not affected (Fig. 5A). For gene expressions, Amhr2, Fshr, Lhcgr and Esr 1 showed significant reduction in model group when compared with control group (Fig. 5B).

\section{The effects of $\mathrm{COH}$ on estrus cyclicity in female offspring}

We recorded the regularity of estrous cycle in young adult female offspring (PND56) to assess the long-term influence of $\mathrm{COH}$. There was no statistical difference in average estrous cycle length (Fig. 6A). However, 

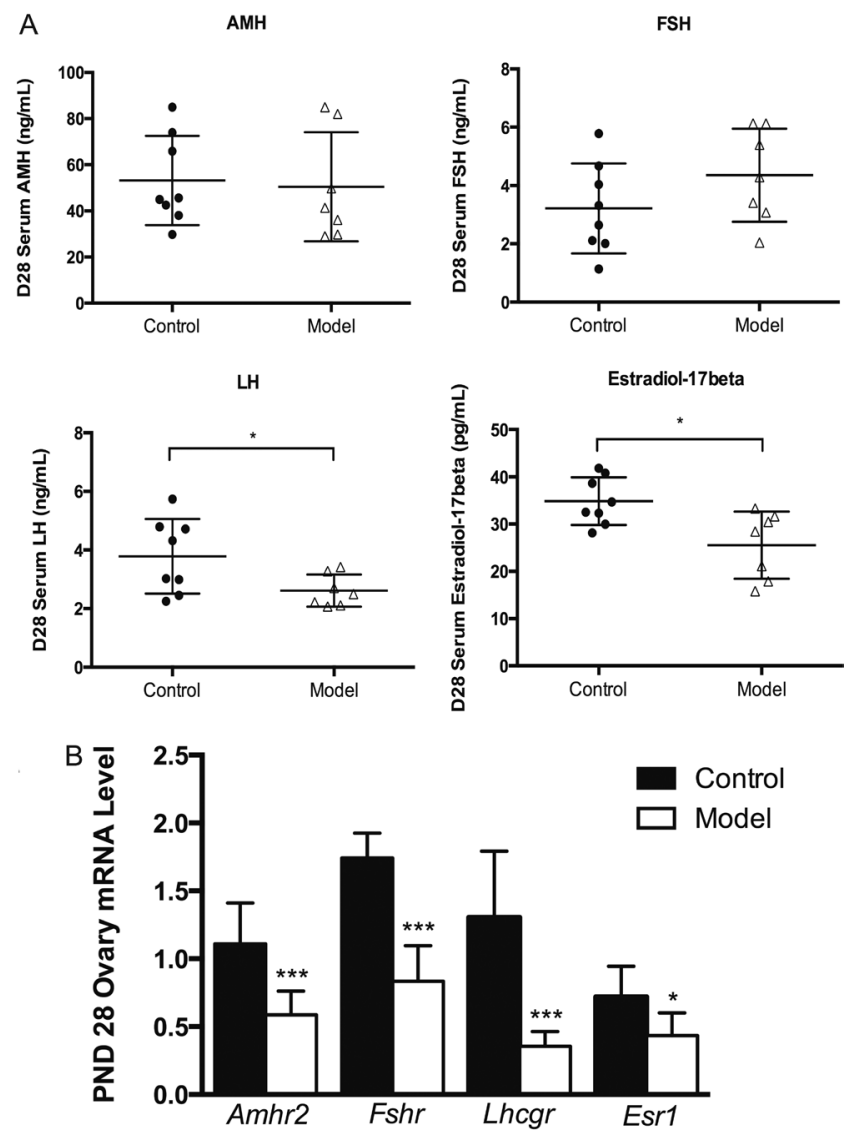

Figure 5 Measurement of serum hormone levels and ovarian hormone receptor gene expressions of female offspring on PND28. (A) Circulating levels of AMH, FSH, LH and E2 in female offspring, $n=7-8,{ }^{*} P<0.05$ vs control group. (B) RT-PCR analysis of Amhr2, Fshr, Lhcgr and Esr1 in ovaries of female offspring. Fold change value was normalized to $\beta$-actin. $n=6-8$, data represent mean \pm S.D.

$* P<0.05$ and ${ }^{* * *} P<0.001$ vs the offspring of naturally conceived mice.

when compared with control group, the young adult female offspring in model group exhibited a growing percentage of days they spent in estrus and a decreased percentage of days in proestrus (Fig. 6B). Representative estrous cycles of the two groups are presented (Fig. 6C and D).

To explore follicle development of young adult female offspring, we performed follicle counting and morphological analysis of ovaries from PND56 female offspring of the two groups. Considering the obvious fluctuations in the number of secondary and tertiary follicles due to cycle selection, we only assess the number of primordial, primary and atretic follicles. Our data showed the ovaries of the offspring of naturally pregnant mice tended to have more primordial follicles $(P<0.05)$ and primary follicles $(P<0.001)$ than $\mathrm{COH}$ female offspring on PND56. However there was no significant difference in the number of atretic follicles (Fig. 7A). This quantitative evaluation was confirmed by the morphological analysis of ovaries of the two groups (Fig. 7B and C).

What is more, overexpression of $\mathrm{AMH}$ in $\mathrm{COH}$ young adult (PND56) female offspring was found. We measured serum $A M H$, ovary $A M H$ protein level, and Amhr2 gene expression in offspring on PND56. In contrast, the serum AMH level (Fig. 8A, $P<0.001$ ) and the ovary $\mathrm{AMH}$ protein expression (Fig. $8 \mathrm{~B}$ and $\mathrm{C}$, $P<0.05)$ were significantly elevated in model group, while the expressions of Amhr2 gene were not statistical differences (Fig. 8D).

\section{Discussion}

Several studies have expressed concerns about the reproductive system being affected by $\mathrm{COH}$ in male offspring (Stouder et al. 2009, Wei et al. 2014). However, to our knowledge, there are few researches focusing on the potential detrimental influence of $\mathrm{COH}$ on the reproductive system of female offspring. The present study focuses on the long-term effects of $\mathrm{COH}$ on female offspring. We discovered, for the first time that $\mathrm{COH}$ in mother could adversely impact the pubertal transition and estrous cyclicity in female offspring.

In our study, we observed that $\mathrm{COH}$ mice exhibited poor pregnancy outcome, suggested by the evidence of higher percentage of pregnancy loss, increased gestational length and a large number of dead fetuses. These are consistent with earlier studies (Ertzeid et al. 1993, Ertzeid \& Storeng 2001, Deng et al. 2013), which demonstrate the decreased implantation rate and the raised fetal mortality in $\mathrm{COH}$ mice. Also, prolonged gestation period is considered to be negative correlated with the number of live fetuses found on delivery day (Ertzeid et al. 1993), as we found a larger number of dead fetuses in $\mathrm{COH}$ group and the gestation period was significantly extended.

Based on the fact that $\mathrm{COH}$ could cause high E2 levels in women throughout pregnancy (Meng et al. 2015), and excess estrogenic exposure during fetal development is harmful to subsequent adult ovarian function (Abbott et al. 2006), we assumed that excessive E2 exposure to fetus caused by $\mathrm{COH}$ might impact on reproductive function of female offspring. Therefore, we first evaluated the pubertal transition and found that delayed puberty was clearly displayed in $\mathrm{COH}$ female offspring, manifesting in delayed first estrus, but not vaginal opening. Although still questionable, first estrus (but not vaginal opening) is considered to be a more reliable indicator of the age at first ovulation (vom Saal 1989), which signifies the transition of puberty and the ability to reproduce. The onset of puberty is driven by the activation of the gonadotropin-releasing hormone $(\mathrm{GnRH})$ neurons from a state of quiescence, which is followed by an estrogen surge and vaginal opening; within a week of vaginal opening, a second peak in 

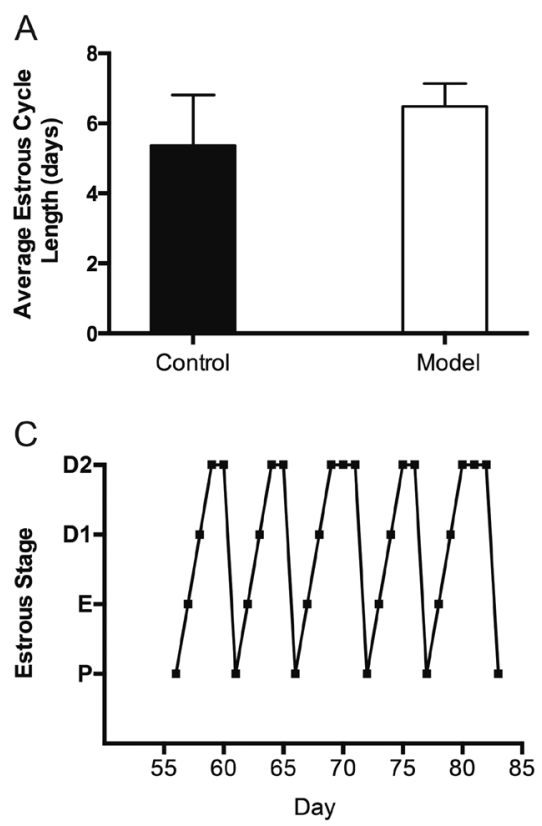
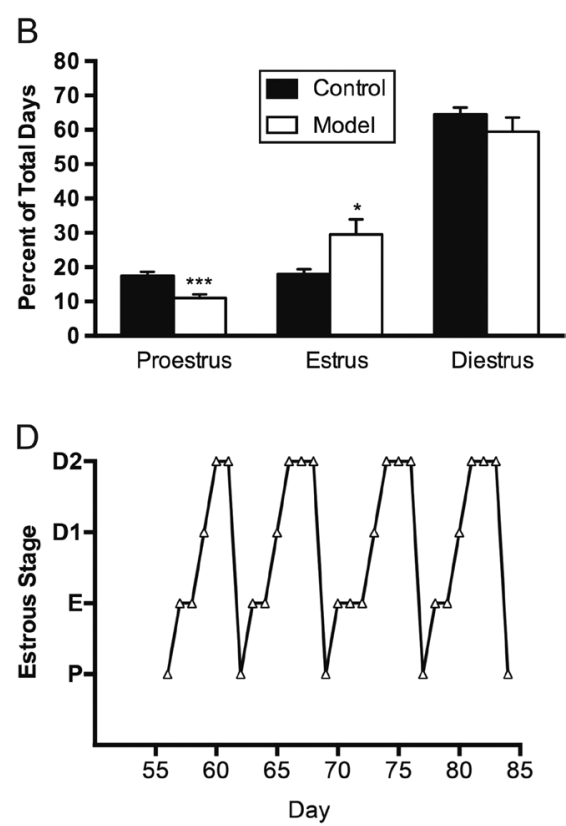

Figure 6 Observation of estrus cyclicity of female offspring from PND56. (A) Comparison of average estrous cycle length of female offspring from control group and $\mathrm{COH}$ group. (B) Comparison of average percentage of time spent in proestrus, estrus and diestrus across 4 weeks. $n=8$, data represent mean \pm s.D. $* P<0.05$ and ${ }^{* * *} P<0.001$ vs the offspring of naturally conceived mice. (C) Representative estrous cycle of control group offspring. (D) Representative estrous cycle of $\mathrm{COH}$ group offspring. P, proestrus; E, estrus; D1, diestrus 1; D2, diestrus 2 . estrogen appears and subsequently the ovulation and first estrus occur, and the transitional period from juvenile to pubertal is completed. Hence, delayed first estrus in $\mathrm{COH}$ female offspring means that the completion of pubertal transition is affected.

At puberty onset, the pulse generator reawakens and induces endocrine changes, which stimulates pituitary gonadotropin secretion, as well as the secretion of gonadal steroid (Villanueva \& Argente 2014). In concert with the modulations of E2 on the pituitary gland, the action of $\mathrm{GnRH}$ triggers the preovulatory surge of $\mathrm{LH}$, which ultimately brings about the first ovulation (Herbison 2016). More specifically, FSH is modulated through pituitary, stimulated by $\mathrm{GnRH}$, and then acts through Fshr to stimulate the proliferation and differentiation of granulosa cell. The responsive follicles produce E2 and express granulosa cell Lhcgr, paracrine signaling induced by $\mathrm{FSH}$ and $\mathrm{LH}$ maintain follicle growth and E2 secretion until an ovulation is triggered by the LH surge, LH then manages granulosa cell function, resulting in terminal rupture of the follicle wall and release of the oocyte (Hillier 2001). In this regard, we measured the hormone levels and gene expressions of ovarian receptors after the activation of the pulse generator (vaginal opening) but before the pubertal transition (first estrus), and found low levels of LH and E2, as well as the reduced mRNA expressions of Fshr, Lhcgr and Esr1 in ovaries of $\mathrm{COH}$ female offspring. The insufficient levels of hormones and the expressions of their receptors indicate that the growth and maturation of the follicles are restricted, which prevents dominant follicle from ovulating, delaying the first ovulation defined as pubertal transition.

It is well known that the atresia of follicles is a hormonally controlled apoptotic process, and the gonadotropins $\mathrm{FSH}$ and $\mathrm{LH}$, the steroids progesterone and estrogen, and locally produced cytokines act as survival factors for follicle atresia via their receptors (Emilia et al. 2002). Accordingly, the reduced hormone levels and mRNA expression of receptors in ovaries of $\mathrm{COH}$ female offspring of PND28 might demonstrate that more follicle atresia might exist in $\mathrm{COH}$ group, which is coincident with our findings showing increased number of atretic follicles in $\mathrm{COH}$ female offspring. What is more, a recent novel study shows that $\mathrm{AMH}$ participates in the regulation of $\mathrm{FSH}$ secretion in immature females, which may be vital for pubertal timing and sexual differentiation (Garrel et al. 2016). No significant differences in FSH and $\mathrm{AMH}$ in $\mathrm{COH}$ female offspring may indicate that the regulation of $\mathrm{FSH}$ is not influenced. However we found that ovarian gene expression of Amhr2 was reduced in $\mathrm{COH}$ female offspring; since $\mathrm{AMH}$ could reduce follicular atresia and Amhr2 is necessary for AMH effect in ovary (Hayes et al. 2016), the decline in expression of Amhr2 may attenuate the anti-atresia effect of $\mathrm{AMH}$ in $\mathrm{COH}$ female offspring, and lead to the increased percentage of atretic follicles.

The apoptosis of granulosa cells is necessary for the atresia of follicles, and one main death ligandreceptor system involved in the induction of apoptosis of granulosa cells is the FASL and FAS system. Female mice treated with FAS-activating antibody facilitated granulosa cell apoptosis and follicular atresia (Hakuno et al. 1996, Sakamaki et al. 1997). In human, the expression of FAS in the granulosa cells increases as atresia progresses (Kondo et al. 1996). Subsequent activation of intracellular signaling (Caspase8 and Caspase3) induces DNA fragmentation. Caspase8 could also activate the mitochondrial apoptotic pathway. BCL2 family members participate in the mitochondria- 

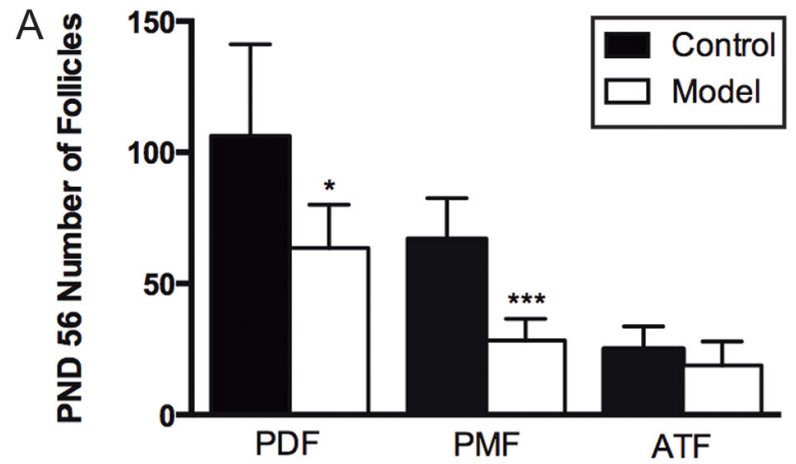

B

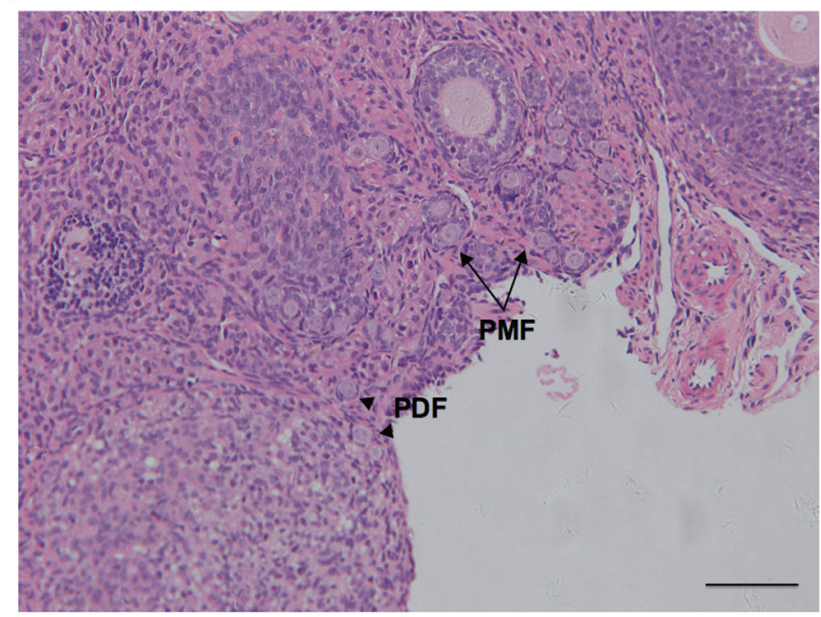

C

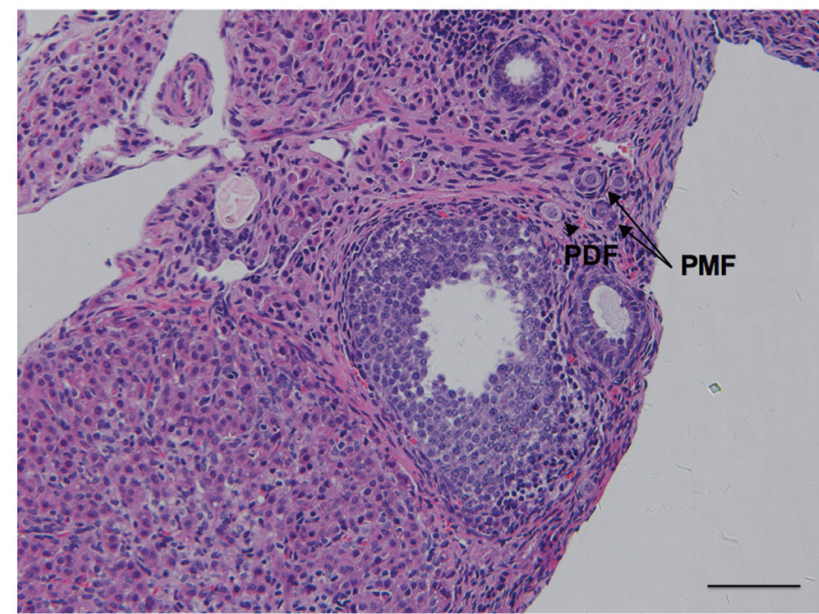

Figure $7 \mathrm{COH}$ female offspring presented less primordial follicles and primary follicles on PND56 than control group. (A) Comparison of percentages of follicles at different developmental stages between control group and $\mathrm{COH}$ group. $n=6$, data represent mean \pm S.D. $* P<0.05$ and $* * * P<0.001$ when compared with control group. PDF, primordial follicles; PMF, primary follicles; ATF, atretic follicles. (B) Representative photographs of ovaries of offspring from control group on PND56, bar $=40 \mu \mathrm{m}$. (C) Representative photographs of ovaries of offspring from $\mathrm{COH}$ group on PND56, bar $=40 \mu \mathrm{m}$. Arrows indicate primary follicles and arrowheads represent primordial follicles. mediated apoptosis of granulosa cells, including both anti-apoptotic (BCL2, B cell lymphoma/leukemia $X$ $(B C L X)$, etc.) and proapoptotic proteins (BAX, BCL2L11, etc.). Overexpression of BCL2 protein decreases granulosa cells apoptosis and enhances folliculogenesis (Hsu et al. 1996). In human ovaries, the expression of BAX is increased in granulosa cells of atretic follicles than that of healthy follicles (Kugu et al. 1998). The same result was found in porcine follicles (Sai et al. 2011). The mitochondrial pathway of apoptosis involves the activation of caspase9, before the subsequent activation of caspase3. Caspase9 is expressed in granulosa cells and discovered to promote follicular atresia in mice and pig (Robles et al. 1999, Matsui et al. 2003). Interestingly, we found the significant increase in FasL, caspase8, Bax, caspase 9 and caspase 3 mRNA levels in female offspring of $\mathrm{COH}$ mice on PND28; however, the elevated protein expression was only detected in cleaved-caspase8, which is one of the main upstream initiators in apoptosis pathway. Apart from caspase3 and caspase9, other caspases such as caspase 6 and caspase7 also act as executioner caspases (Stennicke et al. 1998); thus, it might be possible that other unevaluated caspases were activated by cleaved-caspase8, leading to the execution of apoptotic program. Furthermore, the functional activity of caspase should be considered regardless of the alteration of its quantity.

However, further investigation is needed to uncover the mystery behind the phenotype of delay pubertal transition. Since the hypothalamic-pituitary-gonad (HPG) axis develops during gestation (Herbison 2016), it is unclear whether the development of HPG axis is affected by the excessive exposure to E2 embryonically. Besides, thousands of genes are considered to be involved in the determination of pubertal timing (Lomniczi et al. 2013), and the disturbed patterns of DNA methylation could affect the gene expression coding for proteins vital for the epigenetic reprogramming, which subsequently leads to biological consequences (Stouder et al. 2009). Several studies have suggested that $\mathrm{COH}$ might induce abnormal methylation patterns in oocytes or embryos of mice (Shi \& Haaf 2002, Fauque et al. 2007, Fortier et al. 2008). Thus, another possible reason for the delayed pubertal transition in female offspring might originate from DNA methylation errors in oocytes caused by $\mathrm{COH}$ in mother.

Beyond that, in our findings, disturbed estrous cycle in $\mathrm{COH}$ female young adult offspring reflects that $\mathrm{COH}$ exerts long-term effect on the reproductive system in female offspring. The estrus cycle in mice corresponds to the menstrual cycle in human, and the different stages of estrus cycle are indicative of underlying endocrine changes. During the proestrus phase, defined by a growing level of E2 before ovulation, follicle growth is stimulated by the secretion of $\mathrm{FSH}$, until the peaks in $\mathrm{FSH}$ levels arrive it enters into estrus and signals ovulation. Following the estrus, E2 declines and prolactin level 

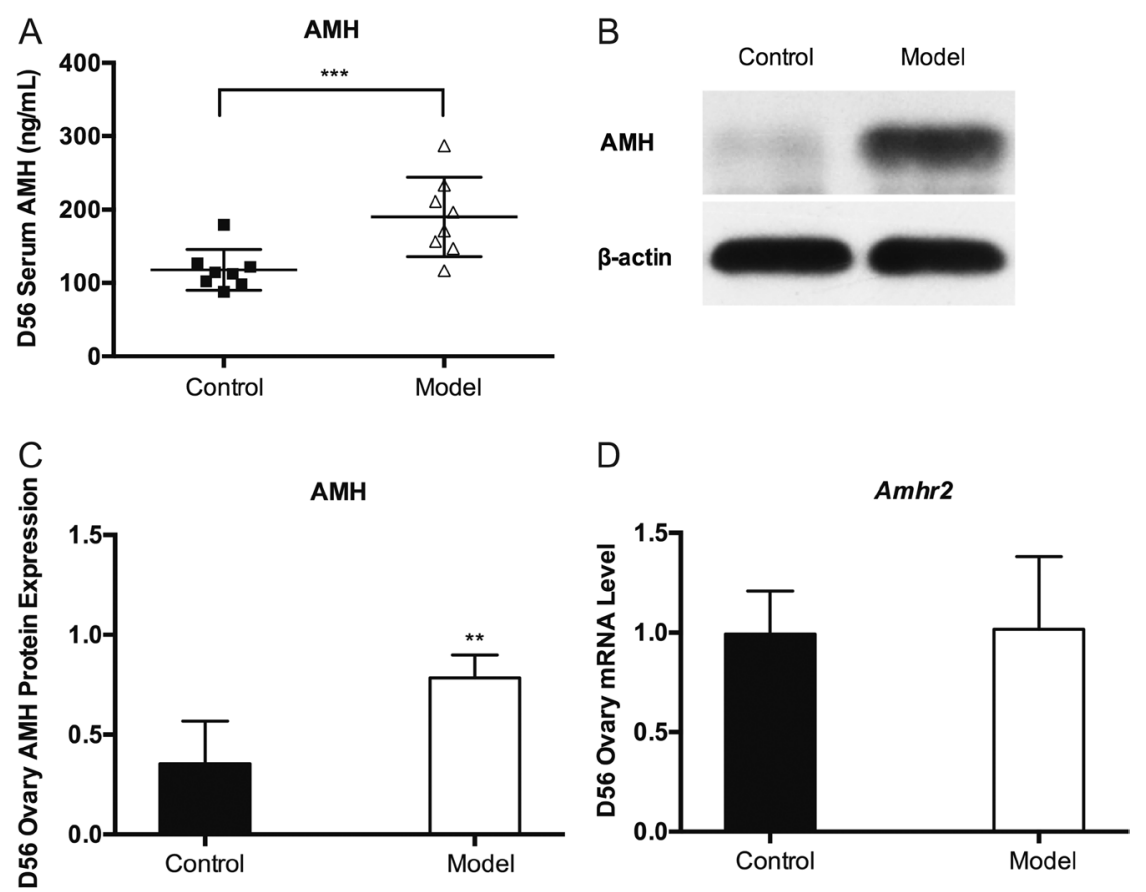

Figure $8 \mathrm{COH}$ female offspring overexpressed $\mathrm{AMH}$. (A) Elevated serum level of $\mathrm{AMH}$ in COH group, $n=8,{ }^{* * *} P<0.001$ vs control group. (B) Western blot showing increased expression of $\mathrm{AMH}$ in ovary of $\mathrm{COH}$ offspring. Three independent experiments were performed. (C) Relative quantity of $\mathrm{AMH}$ protein expression $(n=5)$. (D) Gene expression of Amhr2 in ovaries. Fold change value was normalized to $\beta$-actin. $n=8$, data represent mean \pm S.D. ${ }^{* *} P<0.01$ and ${ }^{* * *} P<0.001$ vs control group. peaks; after the completion of ovulation, there is a rising trend in progesterone hormone level accompanied by a small surge in E2 level as the response to corpus luteum activation. Finally, the circulating progesterone level peaks with the entry into diestrus, and the regression of the corpus luteum results in a sharp decline in progesterone level (McLean et al. 2012). Thus, the disturbance of estrus cycle characterized by relatively shorter proestrus and prolonged estrus implicates the abnormal hormone changes in mice, which reflects the disturbed follicle growth in $\mathrm{COH}$ female offspring.

As FSH, LH, E2, prolactin and progesterone secretions fluctuate with the different stages of estrus cycle, we measured the circulating $\mathrm{AMH}$ level, which was strongly associated with follicle recruitment and relatively stable during the estrus cycle, and discovered elevated level of $\mathrm{AMH}$ in $\mathrm{COH}$ female offspring. As mentioned above, $\mathrm{AMH}$ could prevent follicles from atresia; therefore increased level of $\mathrm{AMH}$ reduces the atresia of follicles in PND56 female offspring of $\mathrm{COH}$ group, presenting no difference of atretic follicles between the two groups on PND56. In rodents, AMH expression is detected in pre-antral follicles, reaches its peak in antral follicles, and attenuates afterward till disappearing in preovulatory follicles (Durlinger et al. 2002). It is well known that $\mathrm{AMH}$ has an inhibitory effect on cycle recruitment of follicles, inhibiting the primordial follicles developing into primary follicles (Zehra et al. 2016); therefore the increased level of $\mathrm{AMH}$ in $\mathrm{COH}$ female offspring overdepresses the development of follicles. According to recent research, it is suggest that $\mathrm{AMH}$ promotes preantral follicle growth while restraining antral follicle maturation and dominant follicle selection in primates
(Xu et al. 2016). However, unlike in primates, AMH has inhibitory effects on both the pre-antral follicle growth and antral follicle maturation in mice (Durlinger et al. 2001). In light of this, we believe that the significant elevated level of $\mathrm{AMH}$ in $\mathrm{COH}$ female offspring implies the restriction of follicle growth and maturation, manifesting in disturbed estrus cycle pattern.

In conclusion, our present report indicates that $\mathrm{COH}$ could lead to poor pregnancy outcome and adversely affect follicle development in female offspring, resulting in delayed pubertal transition and subsequent irregular estrus cyclicity in adulthood. However, further investigations are necessary to explore the underlying mechanisms by which $\mathrm{COH}$ influences the reproduction system of female offspring, whether from the perspectives of imprinted genes expressions or excessive hormone exposure embryonically. And more generations could be involved in studies focused on the $\mathrm{COH}$ offspring. Despite the limitations of our study, our findings do raise the concern of better evaluation of the risks and effects of $\mathrm{COH}$, especially for the reproductive well-being of $\mathrm{COH}$ female offspring.

\section{Declaration of interest}

The authors declare that there is no conflict of interest that could be perceived as prejudicing the impartiality of the research reported.

\section{Funding}

This study was supported by the grant from the National Natural Science Foundation of China (No. 81473494). 


\section{References}

Abbott DH, Padmanabhan V \& Dumesic DA 2006 Contributions of androgen and estrogen to fetal programming of ovarian dysfunction. Reproductive Biology and Endocrinology 4 17. (doi:10.1186/14777827-4-17)

Brinton LA, Kruger Kjaer S, Thomsen BL, Sharif HF, Graubard BI, Olsen JH \& Bock JE 2004 Childhood tumor risk after treatment with ovulation-stimulating drugs. Fertility and Sterility 81 1083-1091. (doi:10.1016/j.fertnstert.2003.08.042)

Chan KA, Tsoulis MW \& Sloboda DM 2015 Early-life nutritional effects on the female reproductive system. Journal of Endocrinology 224 R45-R62. (doi:10.1530/JOE-14-0469)

Deng S, Xu J, Zeng J, Hu L \& Wu Y 2013 Ovarian stimulation leads to a severe implantation defect in mice. Reproductive BioMedicine Online 27 172-175. (doi:10.1016/j.rbmo.2013.03.018)

Detti L, Uhlmann RA, Lu M, Diamond MP, Saed GM, Fletcher NM, Zhang J \& Williams LJ 2013 Serum markers of ovarian reserve and ovarian histology in adult mice treated with cyclophosphamide in pre-pubertal age. Journal of Assisted Reproduction and Genetics 30 1421-1429. (doi:10.1007/s10815-013-0087-x)

Durlinger AL, Kramer P, Karels B, de Jong FH, Uilenbroek JT, Grootegoed JA \& Themmen AP 1999 Control of primordial follicle recruitment by anti-Müllerian hormone in the mouse ovary. Endocrinology 140 5789-5796. (doi:10.1210/endo.140.12.7204)

Durlinger AL, Gruijters MJ, Kramer P, Karels B, Kumar TR, Matzuk MM, Rose UM, de Jong FH, Uilenbroek JT, Grootegoed JA et al. 2001 AntiMüllerian hormone attenuates the effects of FSH on follicle development in the mouse ovary. Endocrinology 142 4891-4899. (doi:10.1210/ endo.142.11.8486)

Durlinger AL, Visser JA \& Themmen AP 2002 Regulation of ovarian function: the role of anti-Müllerian hormone. Reproduction $\mathbf{1 2 4}$ 601-609. (doi:10.1530/rep.0.1240601)

Emilia M, Eva CS, Ruijin S, Bodil S \& Håkan B 2002 Survival factors regulating ovarian apoptosis - dependence on follicle differentiation. Reproduction 123 23-30. (doi:10.1530/rep.0.1230023)

Ertzeid G \& Storeng R 2001 The impact of ovarian stimulation on implantation and fetal development in mice. Human Reproduction 16 221-225. (doi:10.1093/humrep/16.2.221)

Ertzeid G, Storeng R \& Lyberg T 1993 Treatment with gonadotropins impaired implantation and fetal development in mice. Journal of Assisted Reproduction and Genetics 10 286-291. (doi:10.1007/BF01204944)

European IVF-Monitoring Consortium, European Society of Human Reproduction and Embryology, Kupka MS, D'Hooghe T, Ferraretti AP, de Mouzon J, Erb K, Castilla JA, Calhaz-Jorge C, De Geyter C et al. 2016 Assisted reproductive technology in Europe, 2011: results generated from European registers by ESHRE. Human Reproduction 31 233-248. (doi:10.1093/humrep/dev319)

Fauque P, Jouannet P, Lesaffre C, Ripoche M-A, Dandolo L, Vaiman D \& Jammes H 2007 Assisted Reproductive Technology affects developmental kinetics, H19 Imprinting Control Region methylation and H19 gene expression in individual mouse embryos. BMC Developmental Biology 7 116. (doi:10.1186/1471-213X-7-116)

Fortier AL, Lopes FL, Darricarrere N, Martel J \& Trasler JM 2008 Superovulation alters the expression of imprinted genes in the midgestation mouse placenta. Human Molecular Genetics 17 1653-1665. (doi:10.1093/hmg/ddn055)

Gao Z, Zhang G, Yu J, Lu XL, Li JT \& Zhang JM 2014 Superovulation does not affect the endocrine activity nor increase susceptibility to carcinogenesis of uterine and mammary glands of female offspring in mice. Journal of Assisted Reproduction and Genetics 31 1243-1249. (doi:10.1007/s10815-014-0295-z)

Garrel G, Racine C, L'Hote D, Denoyelle C, Guigon CJ, di Clemente N \& Cohen-Tannoudji J 2016 Anti-Mullerian hormone: a new actor of sexual dimorphism in pituitary gonadotrope activity before puberty. Scientific Reports 6 23790. (doi:10.1038/srep23790)

Grasa P, Ploutarchou P \& Williams SA 2015 Oocytes lacking O-glycans alter follicle development and increase fertility by increasing follicle FSH sensitivity, decreasing apoptosis, and modifying GDF9:BMP15 expression. FASEB Journal 29 525-539. (doi:10.1096/fj.14-253757)

Hakuno N, Koji T, Yano T, Kobayashi N, Tsutsumi O, Taketani Y \& Nakane PK 1996 Fas/APO-1/CD95 system as a mediator of granulosa cell apoptosis in ovarian follicle atresia. Endocrinology 137 1938-1948. (doi:10.1210/endo.137.5.8612534)

Hayes E, Kushnir V, Ma X, Biswas A, Prizant H, Gleicher N \& Sen A 2016 Intra-cellular mechanism of anti-Mullerian hormone (AMH) in regulation of follicular development. Molecular and Cellular Endocrinology 433 56-65. (doi:10.1016/j.mce.2016.05.019)

Herbison AE 2016 Control of puberty onset and fertility by gonadotropinreleasing hormone neurons. Nature Reviews Endocrinology 12 452-466. (doi:10.1038/nrendo.2016.70)

Hillier SG 2001 Gonadotropic control of ovarian follicular growth and development. Molecular and Cellular Endocrinology 179 39-46. (doi:10.1016/S0303-7207(01)00469-5)

Hsu SY, Lai RJM, Finegold M \& Hsueh AJW 1996 Targeted overexpression of $\mathrm{BCl}-2$ in ovaries of transgenic mice leads to decreased follicle apoptosis, enhanced folliculogenesis, and increased germ cell tumorigenesis. Endocrinology 137 4837-4843. (doi:10.1210/ endo.137.11.8895354)

Hu XL, Feng C, Lin XH, Zhong ZX, Zhu YM, Lv PP, Lv M, Meng Y, Zhang D, Lu XE et al. 2014 High maternal serum estradiol environment in the first trimester is associated with the increased risk of small-for-gestational-age birth. Journal of Clinical Endocrinology and Metabolism 99 2217-2224. (doi:10.1210/jc.2013-3362)

Klip H, Burger CW, de Kraker, van Leeuwen FE \& OMEGA-Project Group 2001 Risk of cancer in the offspring of women who underwent ovarian stimulation for IVF. Human Reproduction 16 2451-2458. (doi:10.1093/ humrep/16.11.2451)

Kondo H, Maruo T, Peng XJ \& Mochizuki M 1996 Immunological evidence for the expression of the fas antigen in the infant and adult human ovary during follicular regression and atresia. Journal of Clinical Endocrinology and Metabolism 81 2702-2710. (doi:10.1210/jc.81.7.2702)

Kugu K, Ratts VS, Piquette GN, Tilly KI, Tao XJ, Martimbeau S, Aberdeen GW, Krajewski S, Reed JC, Pepe GJ et al. 1998 Analysis of apoptosis and expression of bcl-2 gene family members in the human and baboon ovary. Cell Death and Differentiation 5 67-76. (doi:10.1038/ sj.cdd.4400316)

La Bastide-Van Gemert S, Seggers J, Haadsma ML, Heineman MJ, Middelburg KJ, Roseboom TJ, Schendelaar P, Hadders-Algra M \& Van den Heuvel ER 2014 Is ovarian hyperstimulation associated with higher blood pressure in 4-year-old IVF offspring? Part II: an explorative causal inference approach. Human Reproduction 29 510-517. (doi:10.1093/ humrep/det448)

Livak KJ \& Schmittgen TD 2001 Analysis of relative gene expression data using real-time quantitative PCR and the 2(-Delta Delta C(T)) Method. Methods 25 402-408. (doi:10.1006/meth.2001.1262)

Lomniczi A, Wright H, Castellano JM, Sonmez K \& Ojeda SR 2013 A system biology approach to identify regulatory pathways underlying the neuroendocrine control of female puberty in rats and nonhuman primates. Hormones and Behavior 64 175-186. (doi:10.1016/j. yhbeh.2012.09.013)

Matsui T, Manabe N, Goto Y, Inoue N, Nishihara S \& Miyamoto H 2003 Expression and activity of Apaf1 and caspase- 9 in granulosa cells during follicular atresia in pig ovaries. Reproduction 126 113-120. (doi:10.1530/rep.0.1260113)

McLean AC, Valenzuela N, Fai S \& Bennett SA 2012 Performing vaginal lavage, crystal violet staining, and vaginal cytological evaluation for mouse estrous cycle staging identification. Journal of Visualized Experiments 67 e4389. (doi: 10.3791/4389)

Meng Y, Lv PP, Ding GL, Yu TT, Liu Y, Shen Y, Hu XL, Lin XH, Tian S, Lv M et al. 2015 High maternal serum estradiol levels induce dyslipidemia in human newborns via a hepatic HMGCR estrogen response element. Scientific Reports 5 10086. (doi:10.1038/srep10086)

Prevot V, Rio C, Cho GJ, Lomniczi A, Heger S, Neville CM, Rosenthal NA, Ojeda SR \& Corfas G 2003 Normal female sexual development requires neuregulin-erbB receptor signaling in hypothalamic astrocytes. Journal of Neuroscience 23 230-239.

Robles R, Tao XJ, Trbovich AM, Maravei DV, Nahum R, Perez GI, Tilly KI \& Tilly JL 1999 Localization, regulation and possible consequences of apoptotic protease-activating factor-1 (Apaf-1) expression in granulosa cells of the mouse ovary. Endocrinology 140 2641-2644. (doi:10.1210/ en.140.6.2641)

Sai T, Goto Y, Yoshioka R, Maeda A, Matsuda F, Sugimoto M, Wongpanit K, Jin HZ, Li JY \& Manabe N 2011 Bid and Bax are involved in granulosa 
cell apoptosis during follicular atresia in porcine ovaries. Journal of Reproduction and Development 57 421-427. (doi:10.1262/jrd.11-007H)

Sakamaki K, Yoshida H, Nishimura Y, Nishikawa SI, Manabe N \& Yonehara S 1997 Involvement of Fas antigen in ovarian follicular atresia and luteolysis. Molecular Reproduction and Development 47 11-18. (doi:10.1002/ (SICl)1098-2795(199705)47:1<11::AID-MRD2>3.0.CO;2-T)

Schendelaar P, Van den Heuvel ER, Heineman MJ, La Bastide-Van Gemert S, Middelburg KJ, Seggers J \& Hadders-Algra M 2014 Increased time to pregnancy is associated with less optimal neurological condition in 4-year-old singletons, in vitro fertilization itself is not. Human Reproduction 29 2773-2786. (doi:10.1093/humrep/deu252)

Schieve LA, Devine O, Boyle CA, Petrini JR \& Warner L 2009 Estimation of the contribution of non-assisted reproductive technology ovulation stimulation fertility treatments to US singleton and multiple births. American Journal of Epidemiology 170 1396-1407. (doi:10.1093/aje/ kwp281)

Seggers J, Haadsma ML, Bos AF, Heineman MJ, Keating P, Middelburg KJ, van Hoften JC, Veenstra-Knol HE, Kok JH, Cobben JM et al. 2012 Dysmorphic features in 2-year-old IVF/ICSI offspring. Early Human Development 88 823-829. (doi:10.1016/j.earlhumdev.2012.06.002)

Seggers J, Haadsma ML, La Bastide-Van Gemert S, Heineman MJ, Middelburg KJ, Roseboom TJ, Schendelaar P, Van den Heuvel ER \& Hadders-Algra M 2014 Is ovarian hyperstimulation associated with higher blood pressure in 4-year-old IVF offspring? Part I: multivariable regression analysis. Human Reproduction 29 502-509. (doi:10.1093/ humrep/det396)

Shi W \& Haaf T 2002 Aberrant methylation patterns at the two-cell stage as an indicator of early developmental failure. Molecular Reproduction and Development 63 329-334. (doi:10.1002/mrd.90016)

Stouder C, Deutsch S \& Paoloni-Giacobino A 2009 Superovulation in mice alters the methylation pattern of imprinted genes in the sperm of the offspring. Reproductive Toxicology 28 536-541. (doi:10.1016/j. reprotox.2009.06.009)

Stennicke HR, Jürgensmeier JM, Shin H, Deveraux Q, Wolf BB, Yang X, Zhou Q, Ellerby HM, Ellerby LM, Bredesen D et al. 1998 Pro-caspase-3 is a major physiologic target of caspase-8. Journal of Biological Chemistry 42 27084-27090. (doi:10.1074/jbc.273.42.27084)

Villanueva C \& Argente J 2014 Pathology or normal variant: what constitutes a delay in puberty? Hormone Research in Paediatrics 82 213-221. (doi:10.1159/000362600)

vom Saal FS 1989 The production of and sensitivity to cues that delay puberty and prolong subsequent oestrous cycles in female mice are influenced by prior intrauterine position. Journal of Reproduction and Fertility 86 457-471. (doi:10.1530/jrf.0.0860457)

Wang LY, Le F, Wang N, Li L, Liu XZ, Zheng YM, Lou HY, Xu XR, Chen YL, Zhu XM et al. 2013 Alteration of fatty acid metabolism in the liver, adipose tissue, and testis of male mice conceived through assisted reproductive technologies: fatty acid metabolism in ART mice. Lipids in Health and Disease 12 5. (doi:10.1186/1476-511X-12-5)

Wei ZT, Lu XL, Zhang G, Yu J, Li H, Jia GH, Li JT \& Zhang JM 2014 The long-term effects of superovulation on fertility and sexual behavior of male offspring in mice. Journal of Assisted Reproduction and Genetics 31 555-560. (doi:10.1007/s10815-014-0191-6)

Xu J, Bishop CV, Lawson MS, Park BS \& Xu F 2016 Anti-Mullerian hormone promotes pre-antral follicle growth, but inhibits antral follicle maturation and dominant follicle selection in primates. Human Reproduction 31 1522-1530. (doi:10.1093/humrep/dew100)

Zehra J, Syeda SF, Khalid A \& Rabia M 2016 Anti-Mullerian hormone: above and beyond conventional ovarian reserve markers. Disease Markers 2016 Article ID 5246217. (doi:10.1155/2016/5246217)

Received 18 October 2016

First decision 20 November 2016

Revised manuscript received 26 June 2017

Accepted 7 July 2017 